BULLETIN Bulletin hispanique

HISPANIQUE Université Michel de Montaigne Bordeaux

$112-2 \mid 2010$

Varia

\title{
El problema mapuche
}

¿La fuerza de la ley? o ¿la ley de la fuerza?

\section{Thierry Nouaille}

\section{(2) OpenEdition \\ Journals}

Edición electrónica

URL: http://journals.openedition.org/bulletinhispanique/1269

DOI: 10.4000/bulletinhispanique.1269

ISSN: 1775-3821

\section{Editor}

Presses universitaires de Bordeaux

\section{Edición impresa}

Fecha de publicación: 31 diciembre 2010

Paginación: 775-803

ISBN: 978-2-86781-709-0

ISSN: 0007-4640

Referencia electrónica

Thierry Nouaille, « El problema mapuche », Bulletin hispanique [En línea], 112-2 | 2010, Publicado el 05 enero 2014, consultado el 19 abril 2019. URL : http://journals.openedition.org/bulletinhispanique/1269 ; DOI : 10.4000/bulletinhispanique.1269 


\title{
El problema mapuche: ¿La fuerza de la ley? o ¿la ley de la fuerza?
}

\author{
THIERRY NOUAILLE \\ Université de la Polynésie Française
}

Le peuple mapuche a su résister à l'empire inca et à la couronne d'Espagne grâce à un héritage culturel et une organisation guerrière exceptionnels. Au début du XIXe siècle, la naissance de la république du Chili ouvre une nouvelle ère durant laquelle le peuple originaire va être considéré comme l'ennemi interne. Par conséquent, l'Etat chilien va non seulement utiliser la loi mais aussi la force pour soumettre définitivement l'indigène.

El pueblo mapuche pudo resistir al imperio inca y a la Corona española gracias a una herencia cultural y una organización militar excepcionales. Al principio del siglo XIX, la naciente república chilena abre una nueva época durante la cual el pueblo originario se verá tratado como el enemigo interno. Por ende, el Estado chileno no sólo va a utilizar la ley sino también la fuerza para someter definitivamente al indigena.

The Mapuche people knew how to stand up against the Inca empire and the Spanish Crown thanks to exceptional cultural heritage and warlike organization. At the beginning of the nineteenth century, the birth of the Chilean Republic gave rise to a new era during which the native people were to be regarded as the internal enemy. Consequently, not only was the Chilean government going to use the law, and force as well in order to subjugate the natives once and for all.

Mots-clés : Chili - Mapuche - État - Loi - Force.

Bulletin Hispanique, Tome 112, n 2 - décembre 2010 - p. 775 à 803. 
¿Vái a firmar o no ?- le preguntaba al mapuche uno de los civiles, cada vez que lo hacian emerger, muy congestionado, del agua. La víctima se limitaba a menear la cabeza en gesto de negación. El tormento se prolongó hasta que el mapuche quedó totalmente exánime. Entonces, a un gesto del terrateniente, los civiles procedieron a entintar el dedo pulgar diestro del maniatado y a estampar su huella dactilar en varios papeles ${ }^{1}$.

A fines de diciembre de 1553, muere el primer gobernador de Chile don Pedro de Valdivia en el fuerte de Tucapel, gracias a la industria del jefe mapuche Lautaro. En diciembre del año 1598, la cabeza del gobernador español Martín García de Óñez y Loyola está en la lanza del líder mapuche Pelantaro en la batalla de Curalava. El 15 de diciembre de 1612, los jesuitas Aranda, Vechi y Montalbán son muertos por el jefe Anganamón. Nacida el 12 de febrero de 1541, la ciudad-capital española de Chile (Santiago) es destruida por los jefes guerreros Michimalongo y Quilicanta, el 11 de septiembre del mismo ańo. En 1598, la solidaridad mapuche acaba por dominar a todas las ciudades en el sur del río fronterizo Bío-Bío $\left(37^{\circ}\right.$ de latitud sur). El 14 de febrero de 1655, el levantamiento general de los indígenas destruye todo lo que tenían los españoles al sur del Bío-Bío. Este breve recuerdo muestra la incansable resistencia mapuche para existir y el papel estratégico y mítico del río Bío-Bío hasta nuestros días.

El fracaso de las campañas militares para controlar los territorios al sur del Bío-Bío obliga a los españoles a cortar el país en dos partes y vivir una convivencia limítrofe entre el reino de Chile y el pueblo mapuche: en el norte del Bío-Bío, están las tierras conquistadas mientras que al sur, siguen permaneciendo las sociedades indígenas reconocidas independientes por la corona española. Hay que esperar el siglo XIX para observar las nuevas armas utilizadas, esta vez, por el gobierno chileno, para vencer a los mapuches. El 12 de febrero de 1818, la declaración de la independencia de Chile marca una nueva etapa jurídica referente al problema mapuche. El Estado, en su voluntad de desarrollar una política de consolidación territorial, utiliza la ley para alcanzar un objetivo clave: incorporar totalmente las tierras del pueblo mapuche a la jurisprudencia del Estado chileno, a través de una colonización jurídica legal occidental. El 4 de marzo de 1819, Bernardo O’Higgins Riquelme, primer Jefe del Estado de Chile independiente y considerado como uno de los Padres de la Patria, tomó una decisión que debía influir en la vida

1. Aníbal Barrera, El grito mapuche (una historia inconclusa), editorial Grijalbo, Santiago de Chile, 1999, p. 5-6. Cuando tenía diez años, Daniel Salinas Muñoz fue testigo de vista de la escena. Hoy en día, es el director del diario Renacer de Angol. 
y el porvenir de los indígenas: desde ahora, los mapuches son «ciudadanos chilenos, y libres como los demás habitantes del Estado» ${ }^{2}$ pero, a pesar de esa buena intención, significaba también que ahora estaban expuestos a la ley. Aquella incorporación unilateral al aparato jurídico chileno marcó «el punto de partida de la relación entre el Estado-Nación y el pueblo mapuche» ${ }^{3}$.

Por otro lado, sabemos que la conquista de Chile se hizo con la sangre de los indios, y más particularmente, la de los mapuches que eran los más rebeldes. Los españoles han utilizado frecuentemente la fuerza para romper la resistencia mapuche. El antiguo lema «imponerse por la fuerza» ha sobrevivido hasta hoy, retomado por las autoridades chilenas para domar la fogosidad indígena. Por ello, el objetivo del presente trabajo es mostrar de qué manera el Estado chileno ha utilizado la ley por un lado, y la fuerza por otro, para ocupar las tierras mapuches y romper su universo familiar, cultural y social.

\section{LA FUERZA DE LA LEY}

Es de recalcar primero la fuerza del símbolo de la tierra para la Comunidad mapuche. En efecto, forma parte de ellos ocupando un lugar preferente en su cosmovisión. El concepto de territorio en la cultura mapuche es muy preciso: Wallmapuche es toda la tierra habitada por las comunidades. El espacio en donde nace y se funda dicha cultura, en donde tiene vigencia el Mapudungun, habla de la tierra. Es el espacio en el cual se tiene conocimiento de su orden y estructura, del Meli Wiltran Mapu ${ }^{4}$. Ahora bien, es de observar que a partir del siglo XIX hasta la época actual, las tierras han sido el blanco principal de las autoridades chilenas siendo la ley el arma utilizada.

\section{I.1 Entre Títulos y decretos destructores}

Después del exilio de Bernardo O’Higgins, el nuevo Director Supremo de la nación fue Ramón Freire. Su gobierno había aprobado una nueva

2. Instituto de Estudios Indígenas de la Universidad de la Frontera, Informe del Programa de Derechos Indígenas en Chile, LOM ediciones, Chile, 2003, p. 159.

3. Ruth Durán, Claudio González, Andrés Tello, La comunidad mapuche: colonización jurídica-legal y resistencia del estar en común, Departamento de Sociología y Antropología, Centro Regional de Estudios Étnicos y Rurales (CREER), Universidad de Concepción, 2006, p. 3.

4. El Meli Wiltran Mapu representa los cuatro puntos cardinales de la Tierra y, correlativamente, las cuatro estaciones del año. Es la simbología que lleva dibujada el kultrun, tambor ritual de las machis. 
Constitución mediante la cual creaba un Senado con doce miembros, cuyo encargo consistía en elaborar los proyectos de ley y los reglamentos de dicha Constitución. El 10 de junio de 1823, los Títulos de Comisario ${ }^{5}$ representaron la primera arma legal utilizada por el Estado. El artículo 3 de la ley estipulaba que lo actual poseído según ley por los indígenas se les declara en perpetua y segura propiedad, lo que muestra el interés del legislador por el desarrollo de la propiedad privada y no por el aspecto social y cultural de los mapuches. En cuanto al artículo 4, éste añadía «que las tierras sobrantes se sacarán a pública subasta» ${ }^{6}$ lo cual significa que el individuo que hacía la mejor oferta se quedaba con las tierras indígenas. Además, se nombraba un funcionario llamado Consejero de Indios, cuya misión era instruirse de los pueblos de indios que existían en la provincia. En resumidas cuentas, en diez años, observamos una progresión considerable de la estrategia jurídica-estatal porque el $1^{\circ}$ de julio de 1813 , una ley ordenaba la creación o establecimientos de «villas para indígenas» ${ }^{7}$ mientras que en 1823 «se dicta una ley que fijaba el procedimiento para la venta de tierras mapuches ${ }^{8}$.

Esta política de recuperación de ciertas tierras indígenas se puso concretamente en marcha a partir de 1824 en la zona huilliche del oeste de Osorno9. Resulta que las tierras sin títulos de propiedad fueron consideradas como fiscales, y, por consiguiente, entregadas en mayoría a los colonos alemanes que habían penetrado en esta zona en $1858^{10}$. En efecto, en 1844 se dicta la primera ley de colonización extranjera y al ańo siguiente el gobernador Bernardo Philippi viaja a Europa para materializar esta política. A continuación, la ley del 2 de julio de 1852 era la obra del presidente Manuel Montt ${ }^{11}$ y su Ministro Antonio Varas que decía que los territorios

5. Esos títulos recibían esa denominación por ser entregados por el Comisario de Naciones, autoridad que había sido creada durante la Colonia.

6. Aukiñ Wallmapu Ngulam, El pueblo mapuche, su Territorio y sus Derechos, editorial Kolping, Temuco, 1997, p. 53.

7. Domingo Colicoy Aniulén, Estado chileno - sociedad mapuche, VII Congreso Internacional del CLAD sobre la reforma del Estado y de la Administración Pública, Lisboa, Portugal, 2002, p. 2.

8. Idem.

9. Las tierras situadas al este de Osorno habían quedado en poder de los huenteches (gente de los llanos conocida por las denominaciones de «arribanos» $\mathrm{y}$ «moluches») de acuerdo con el tratado de 1793.

10. Así, más tarde, los alemanes expandirían sus propiedades con las tierras arrebatadas a los indígenas.

11. La actitud del presidente Manuel Montt seguía la corriente general y confirmaba las intenciones de los políticos chilenos con respecto a los mapuches. Paradójicamente, cabe señalar que durante los diez años de su gobierno, Chile avanzó en el plano de la educación. Los jesuitas volvieron a Chile y la Misión de los Capuchinos ingresó a la Araucanía. Se 
mapuches debían anexarse al Estado de Chile. El artículo número uno de esta ley decía:

Establécese una nueva provincia con el nombre de Arauco que comprenderá en su demarcación los territorios de indígenas, situados al sur del río Bio-Bio y al norte de la provincia de Valdivia ${ }^{12}$.

Acto seguido, la ley del 14 de marzo de 1853, promulgada por el mismo gobierno, que legislaba sobre la compra y venta de las tierras indígenas fue aún más reveladora ${ }^{13}$. Los mapuches como debe entenderse no tenían idea alguna del proceso mercantil propio de los huincas (vocablo de origen mapuche que significa "hombre cristiano o extranjero») y naturalmente iban a ser presa del engaño, de la compra dolosa y fraudulenta. Cómo interpretar esta ley sino como otro instrumento para la eliminación premeditada de la Comunidad mapuche. A partir de ese momento, empezó realmente la contradicción de la nacionalidad chilena con sus antepasados. La ley del 4 de diciembre de 1855 permitió que continuasen las enajenaciones de tierras mapuches-huilliches normalizando la compra y venta de tierras en la provincia de Valdivia y Llanquihue. Entre 1853 y 1863, se dictaron nueve decretos sobre el tema compra-venta de tierras indígenas, con la misma voluntad: el avasallamiento de las tierras de los indios por parte de los colonos y comerciantes amparados por el Estado Chileno.

publicó también el Código Civil Chileno en 1855, obra de Andrés Bello.

12. Alejandro Lipschutz, La comunidad Indígena en América y en Chile, Editorial Universitaria, Santiago de Chile, 1959.

13. Noté fragmentos muy importantes para entender mejor el objetivo de la ley del 14 de marzo de 1853:

\section{Considerando:}

1.- "Que las ventas de terrenos indígenas sin intervención de una autoridad superior, que proteja a los vendedores contra los abusos que pudieran cometerse para adquirir sus terrenos y que dé garantía a los compradores contra los pretextos u objeciones de falta de pago o falta de consentimiento que, a veces, sin fundamentos se alegan por los indígenas, son origen de pleitos y reclamaciones que producen la inseguridad e insubsistencia de las propiedades raíces de esos territorios".

2.- "Que es esencial, para que la autoridad que gobierna a los indígenas se conserve en condición de independiente y sin intereses que la embaracen del desempeño de sus deberes, que no entre con ellos en ninguna especie de negocios o contratos».

Se resuelve: "Toda compra de terrenos hecha a indígenas o de terrenos situados en territorios de indígenas debe verificarse con intervención del Intendente de Arauco y del Gobernador de Indígenas del territorio respectivo que el Intendente comisione especialmente para cada caso. La intervención del Intendente o del funcionario comisionado por él, tendrá por objeto asegurarse de que el indígena que vende le pertenece realmente y de que sea pagado o asegurado debidamente el pago del precio convenido». 
En 1857, Chile pasó una crisis económica y de presión por el aumento de las exportaciones de cereales (en particular el trigo) a California y Australia, surgiendo la necesidad de expandir el territorio estatal con tierras productivas. Ahora bien, a mediados del siglo XIX, los mapuches que vivían entre los ríos Bío-Bío y Toltén, seguían manteniendo su autonomía territorial. Esto viene a ser rápidamente una codiciosa búsqueda de tierras por parte de los gobiernos chilenos, y sólo faltaba una nueva estrategia para dar una legitimidad a los hechos. Los Títulos de Merced, dictados el 4 de diciembre de 1866, simbolizaron el fruto de esta reflexión formando parte de la llamada Política de Radicación. Esta Política de Radicación consistía en juntar en un lugar determinado a las unidades locales de las comunidades mapuches, limitándolas en su manejo amplio de territorios y confinándolas en espacios reducidos y arbitrariamente determinados. El objetivo inconfesable era incrementar actividades distintas de la agricultura (la caza, la pesca y la recolección que formaban parte de su economía) impidiendo la rotación de los suelos (esas medidas se parecían mucho a la antigua política de reducciones). Por otra parte, al levantar el plano de las tierras de cada familia, las autoridades otorgaban un título a nombre del jefe, lo cual permitió liberar tierras para entregarlas a los colonos.

La ley de 1866 fue el comienzo de lo que más tarde iba a caracterizar toda la legislación indigenista chilena. Por ejemplo, notamos la no priorización de las comunidades frente a los títulos individuales, el carácter enajenable de las tierras indígenas, la posible división de las comunidades, el nombramiento de un intermediario estatal ${ }^{14}$ para representar los derechos de los mapuches en todas circunstancias y especialmente «en el deslinde de sus posesiones i en todos los contratos traslaticios de dominio» ${ }^{15}$. Por otro lado, dicha ley favoreció una colonización nacional y extranjera, y muchas tierras de origen mapuche fueron tomadas por colonos blancos ${ }^{16}$. Así mismo tenemos que tomar en cuenta el que, a través de esta ley del gobierno de José Joaquín Pérez (diciembre de 1866), el Estado chileno pasaba a ser el único propietario de las tierras indígenas prohibiéndose toda venta de tierras mapuches a particulares. Así, el Estado se hizo el único comprador y vendedor de tierras, radicando a las familias mapuches en Reservaciones gracias a un Título de Merced de Tierras:

14. El Protector de Indígenas era generalmente un colono con intereses concretos en la agricultura.

15. Aukiñ Wallmapu Ngulam, El pueblo mapuche..., p. 54.

16. Esas tierras estaban a lo largo del río Bío-Bío, de la costa sur de Concepción y en las áreas norte y sur de Valdivia. 
Si una octava parte de los indígenas cabezas de familia de la reducción reconocida como propietaria del terreno pidiese que se le asigne determinadamente lo que le corresponde, los Ingenieros procederán a hacer la división y demarcación de los límites, asignando al cacique el triple de la parte del terreno que se asigne a la cabeza de familia ${ }^{17}$.

Por primera vez la Ley Indígena hace referencia a la división de la tierra. Los decretos seis y siete introducen además dos nociones claves: el concepto de Reducción, y división de la tierra. Con tantas leyes sucesivas, ¿podemos pensar todavía que el propósito no era el de acabar con la nación mapuche asimilándola a los modos de vida de la sociedad chilena? En el libro del profesor mapuche Martín Alonqueo Piutrin ${ }^{18}$, encontramos una respuesta pragmática a los Títulos de Merced:

Después de un largo tiempo les entregaban un retazo de suelo bajo el título de Merced de Tierra en una Reducción cuya extensión nominal es de tres hectáreas, sin individualización ni división, al estilo de las encomiendas, en tiempo de los españoles, con la única diferencia en que el jefe era ahora un mapuche, bajo el título de cacique para que ahí viviera a su propia suerte y abandono. En medio de las asechanzas eternas de los voraces esquiladores que nunca se llenan ni descansan de robar y usurpar lo poco y nada que le va quedando a los mapuches.

Los Títulos de Merced fueron un arma que organizaba al arbitrio del Estado lotes de hijuelas en torno a un cacique reconocido como tal. Este nuevo orden desestructuró la organización política y social ancestral al someter a lonkos y linajes a la autoridad del papel. El otorgamiento legal de privilegios sólo a algunos de los miembros de las comunidades, fue una nueva estrategia política importante para dar nacimiento a conflictos y divisiones internas entre los indios mapuches. Esto sobreentendía un rompimiento y degradación progresiva de su forma de vida en comunidad y «la radicación sedentarizó a los mapuches cambiando su actividad económica de ganadera a agrícola, debido al reducimiento de tierras» ${ }^{19}$.

Concretamente, todas las redistribuciones de tierras se ampararon detrás de una colonización jurídica que se tradujo por una historia de despojos y

17. Aukiñ Wallmapu Ngulam, El pueblo mapuche..., p. 54.

18. Martín Alonqueo Piutrin, Mapuche Ayer y Hoy, Editorial Padre las Casas, Temuco, 1985.

19. Instituto de Estudios Indígenas de la Universidad de la Frontera, Informe..., p. 162. 
contiendas. Los Títulos de Merced fueron una manipulación estatal porque no existía la forma jurídica válida que autorizara a alguien apoderarse de esas tierras: el objetivo de la oligarquía era la ocupación del sur con colonos que harían producir la tierra para la expansión económica. José Bengoa acaba enfatizando que para los gobiernos, el problema indígena «tendría solución con el cambio y división de la propiedad comunal a propiedad individual» ${ }^{20}$.

La segunda Ley de Títulos de Merced del 4 de agosto de 1874 fue un nuevo golpe dirigido contra los derechos mapuches. Por ejemplo, que a los mapuches que no hubieran probado la posesión de sus tierras «se les considere como colonos a fin de adjudicarles parcelas individuales» ${ }^{21}$. Además, el Estado siguió su política de colonización favorizando a los inmigrantes de Europa. La última Ley de Títulos de Merced data del 20 de enero de 1883. En contraste con la generosidad que mostraba la ley anterior con los colonos, para los indígenas ésta decía que

si el título de la comisión tuviere que extender a favor de los indígenas o una reducción pasare de 300 hectáreas, deberá elevarse el expediente en consulta al Presidente de la República, acompañando plano del terreno a que el título se refiere ${ }^{22}$.

En 1927, se dicta una ley que concluye la entrega de Títulos de Merced creando el Tribunal Especial de División de Comunidades Indígenas. El punto importante fue que se daba un plazo de diez ańos durante el cual las tierras eran inalienables y que luego, se podrían vender a partir de esas divisiones. Hay que esperar verdaderamente el año 1961, para notar la llegada de una nueva legislación completa con el objetivo de resolver jurídicamente el problema de la usurpación de tierras. Lo que llama particularmente la atención es la creación de una nueva categoría:

Se tendrá por particulares a aquellas personas que reclamen derechos que no emanen directa o inmediatamente de un título de merced, ni la calidad de herederos que figuren de estos títulos ${ }^{23}$.

Nos podemos preguntar sobre las consecuencias de este nuevo decreto. En efecto, a petición de cualquier demandante (indígena o particular), se

20. José Bengoa, Historia de un conflicto: El Estado y los Mapuches en el Siglo XX, Editorial Planeta, Chile, 1999, p. 164.

21. Aukiñ Wallmapu Ngulam, El pueblo mapuche..., p. 54.

22. Idem.

23. Ruth Durán, Claudio González, Andrés Tello, La comunidad mapuche..., p. 6-7. 
dividiría la propiedad territorial de la comunidad al pasar a un régimen de propiedad privada, entregándoles Títulos a indígenas y a particulares. Pero ¿qué se oculta realmente detrás de esta nueva orientación jurídica? La respuesta es sencilla: entre 1931 y 1971 se dividieron 832 comunidades (o reducciones) de las casi tres mil existentes, y a pesar de la declaración de la inalienabilidad de las tierras se estima que cien mil hectáreas (un quinto del total de las tierras mapuches) se enajenaron a no indígenas durante aquel período. En resumidas cuentas, el objetivo estatal es el mismo: reducir poco a poco el territorio mapuche.

Después del Golpe de Estado de 1973, entramos en un segundo período en que extreman las políticas de usurpación y aniquilación en contra del pueblo mapuche. En 1979, se impuso una única política indígena con el claro objetivo de dividir las reservas para servir el neoliberalismo chileno y los intereses individuales. La dictadura militar se propuso terminar con el problema mapuche negando la calidad de tierra indígena como lo muestra muy bien Claudia Ortiz precisando que «dejarán de ser tierras indígenas e indígenas sus habitantes ${ }^{24}$. Al final de la dictadura, el balance era el siguiente: sólo dieciocho comunidades se habían negado a aceptar la división, alrededor de dos mil fueron divididas sin apelación, de las que resultaron setenta y dos mil hijuelas individuales y más de cuatrocientas sesenta mil hectáreas de tierras indígenas divididas. Si agregamos las mil que fueron divididas antes, tenemos alrededor de tres mil comunidades que fueron divididas bajo los decretos de ley inmunitarios ${ }^{25}$. La represión fue muy dura con los mapuches: mientras que la detención por sospecha en las ciudades era de un $6 \%$ de la población, en zonas mapuches alcanzaba los $20 \%{ }^{26}$. El Informe de la Comisión Nacional de Verdad y Reconciliación va más lejos afirmando que las grandes violaciones de los derechos humanos en la Araucanía tuvieron un importante componente racista, y directa relación de coerción y persecución contra aquellos que habían participado en el proceso de la Reforma Agraria ${ }^{27}$.

24. Claudia Ortiz, El derecho de Dominio en la Legislación Indígena, Memoria de Grado de Licenciada en Ciencias Jurídicas y Sociales, Universidad de Concepción, 2001, p. 66.

25. Gabriel Salazar, Historia contemporánea de Chile, LOM ediciones, Chile, 1999, Tomo II, p. 166.

26. José Bengoa, Historia de un conflicto..., p. 163.

27. Martín Correa, La Reforma Agraria y las Tierras Mapuches: Chile 1962-1975, LOM ediciones, Chile, 2005, p. 245. 


\section{I.2 Las Leyes Indígena y Antiterrorista}

\section{I.2.1 La Ley Indígena número 19.253}

El pueblo mapuche siempre hizo patentes esfuerzos por mantener su vigencia cultural y hay que decir las cosas claramente: no se sienten chilenos a pesar de una nacionalidad legal estampada en los documentos civiles. El 28 de septiembre de 1993, se promulgó la Ley Indígena número 19.253, verdadero fruto de las promesas del candidato presidencial Patricio Aylwin que quería establecer una relación diferente con los pueblos indígenas de Chile. Me di cuenta, en efecto, de que esa ley contenía algunas innovaciones de importancia. El primer punto, muy valioso en lo que se refiere al reconocimiento de los indios, se halla en el párrafo $3^{\circ}$, artículo 8:

Se considera falta la discriminación manifiesta o intencionada en contra de los indígenas, en razón de su origen y su cultura. El que incurriere en esta conducta será sancionado con multa de uno a cinco ingresos mínimos mensuales ${ }^{28}$.

Esta ley me parece histórica si tomamos en cuenta todas las agresiones racistas infligidas a los mapuches. No obstante, podemos dudar de la real aplicación de esta medida cuando vemos lo que pasa diariamente en Chile con respecto a la Comunidad mapuche: el racismo está por todas partes. El segundo punto que llama la atención es el respeto de la cultura de los indios, punto inevitablemente relacionado con el artículo presentado más arriba:

Los indígenas gozarán del derecho a ejercer comunitariamente actividades en los sitios sagrados o ceremoniales, cementerios, canchas de guillatún, apachetas ${ }^{29}$, campos deportivos y otros espacios territoriales de uso cultural o recreativo, que sean propiedad fiscal ${ }^{30}$.

28. La Ley Indígena $n^{\circ}$ 19.253, Editorial Pillan, Chile, 1993, Título I, párrafo $3^{\circ}$, artículo 8.

29. Las pachetas son montículos de piedras que erigen los campesinos andinos en ciertos puntos del camino a través de las montañas cordilleras para honrar a la Pacha Mama. En ellos, dejan a veces sus acullidos (bocados de hojas de coca), la chicha (bebida alcohólica que resulta de la fermentación del maíz), la aloja (cerveza de algarroba blanca), o una piedra que levantan en el camino y que pasa a engrosar el montículo. A veces, la pacheta suele ser una sola piedra grande y de color blanco, ya para ser visible, ya por alguna razón simbólica: es una especie de posada espiritual de los caminantes.

30. La Ley Indígena n 19.253, Editorial Pillan, Chile, 1993, Título II, párrafo $1^{\circ}$, artículo 19. 
Es de notar el espacio de libertad que se les abre para que ejerzan su cultura, aspecto en relación con el artículo 7 que alude a la responsabilidad del Estado que «tiene el deber de promover las culturas indígenas, las que forman parte del patrimonio de la Nación chilena $»^{31}$ y el título general del párrafo $1^{\circ}$ que habla de «reconocimiento, respeto y protección de las culturas indígenas ${ }^{32}$. Aunque observemos esfuerzos notables a favor de la cultura de los indios, debemos mencionar también el control permanente del Estado y de su administración jurídica, a través de algunas palabras presentes en las leyes como "que sean propiedad fiscal» o "que forman parte patrimonio de la Nación chilena». O sea que el Estado está presente y para sobrevivir culturalmente, el pueblo mapuche debe someterse a su poder.

Por otra parte, si acabamos de ver la relativa libertad indígena concedida por las autoridades chilenas, las cosas son muy diferentes cuando se habla de tierras, aspecto clave de las reivindicaciones mapuches. Así, pues, los artículos 12 y 13 definen como tierras indígenas aquellas provenientes de las normas legales que históricamente han existido en el país, como los Títulos de Comisario y de Merced:

Son tierras indígenas:

$1^{\circ}$ Aquellas que las porronas o comunidades indígenas actualmente ocupan en propiedad o posesión provenientes de los siguientes títulos:

Títulos de Comisario de acuerdo a la ley de 10 de junio de 1823.

Títulos de Merced de conformidad a las leyes de 4 de diciembre de 1866; de 4 de agosto de 1874 , y de 20 de enero de $1883^{33}$.

y

Las tierras a que se refiere el artículo precedente, por exigirlo el interés nacional, gozarán de la protección de esta Ley y no podrán ser enajenadas, embargadas, gravadas, ni adquiridas por prescripción, salvo entre comunidades o personas indígenas de una misma etnia ${ }^{34}$.

Por el momento, desconocemos cuáles son las implicancias legales y prácticas de esta disposición. Sin embargo, la Junta General de caciques de Butahuillimapu, organización de tipo tradicional que representa a las comunidades huilliches, hasta el día de hoy, asevera la pérdida de sus tierras ancestrales y exige una solución concreta al problema de la propiedad y la escasez de su tierra. Yendo más lejos, no es una mentira afirmar que hoy, esos

31. Ibid., Título I, párrafo $3^{\circ}$, artículo 7 .

32. Ibid., Título IV, párrafo $1^{\circ}$.

33. Ibid., Título II, párrafo $1^{\circ}$, artículo 12 .

34. Ibid., Título II, párrafo $1^{\circ}$, artículo 13 . 
títulos ya no existen porque fueron anulados con la finalidad de dividir las tierras en parcelas individuales y una parte considerable de este reparto fue usurpada por particulares y empresas. Hoy, debemos aceptar el hecho de que la relación entre el Estado chileno y la sociedad mapuche no es ideal. Sin embargo, no se pueden negar algunos avances en la actual legislación indígena número 19.253. Se diferencia sustancialmente de los cuerpos de la legalidad tradicional conocida en Chile, que siempre se caracterizó por un tratamiento bajo régimen de igualdad jurídica a la población indígena, desconociendo tantos derechos consuetudinarios y la especificidad cultural. Con esta nueva ley, ha empezado un período distinto puesto que se intenta aportar una respuesta a los temas centrales de la problemática: tierra, desarrollo, cultura y educación o enfrentarlos.

La ley creó también un Fondo para Tierras y Aguas Indígenas que puede otorgar subsidios a las personas y comunidades indígenas para la adquisición de tierras, pudiendo también financiar la solución de problemas de tierras, constituir, regularizar o comprar derechos de agua y las obras para la obtención y uso del recurso. La Corporación Nacional de Desarrollo Indígena (CONADI) es el organismo encargado de promover, coordinar y ejecutar la acción del Estado, y deberá

velar por la protección de las tierras indígenas a través de los mecanismos que establece esta ley y posibilitar a los indígenas y sus comunidades el acceso y ampliación de sus tierras y aguas a través del Fondo respectivo ${ }^{35}$.

El presupuesto otorgado a la CONADI y a su Fondo para Tierras y Aguas Indígenas fue insuficiente para solucionar los problemas más urgentes de la demanda. En efecto, como lo pone de realce Domingo Colicoy Aniulén, «en 1994 este Fondo tuvo un presupuesto de \$2.100 millones de los cuales destinó \$1.818 millones a compras de tierras. En 2002, el presupuesto del fondo es de $\$ 14.106$ millones, de los cuales $\$ 11.155$ millones, se destinan a compra de tierras ${ }^{36}$. A pesar de todo, los esfuerzos consentidos en el interés del Estado no deben hacernos caer en la candidez. La ley pretendía dotar de tierras a las comunidades mapuches mediante la asignación gratuita de predios fiscales. No obstante, es facil adivinar que las areas fiscales que existían después de ciento treinta años de colonización de tierras en alto rendimiento, eran de escaso valor agrícola o forestal. A este respecto, es útil recordar una triste realidad que denunció el ministro de Bienes Nacionales

35. Ibid., Título IV, párrafo $1^{\circ}$, artículo 39, e.

36. Domingo Colicoy Aniulén, Estado chileno..., p. 6. 
(Jorge Heine) a través del diario Austral de Temuco en 1999, reconociendo que «lamentablemente, en la Novena Región prácticamente no nos quedan ya tierras fiscales» ${ }^{37}$. Cabe señalar que la novena región, la Araucanía cuya capital es Temuco, simboliza el corazón de la etnia originaria chilena, la nación mapuche, y está compuesta de las provincias de Malleco y Cautín.

Se debe notar el aspecto dudoso de algunas medidas de la Ley número 19.253 que en vez de juntar al pueblo indígena, intenta dividirlo. Si tomamos, por ejemplo, la definición de las asociaciones indígenas, es «la agrupación voluntaria y funcional integrada por, a lo menos, veinticinco indígenas que se constituyen en función de algún interés y objetivo de común $»^{38} \mathrm{y}$ "obtendrán personalidad jurídica»" ${ }^{39}$ pero «no podrán atribuirse la representación de las comunidades indígenas ${ }^{40}$. Eso plantea el problema de la falta de representatividad de las organizaciones indígenas que consagra la ley. Frente a todas esas incoherencias, en marzo de 1999, el diputado por Temuco, Francisco Huenchumilla, propuso al precandidato presidencial (senador Andrés Zaldívar) que se revisara la Ley Indígena sobre la base de un real aporte de las etnias originarias. Me llama mucho la atención su visión de hombre político; al confiarse a un periodista del diario El Mercurio dijo:

Se requiere tener una visión de Estado para abordar el tema; de lo contrario, en diez años más sí vamos a tener un problema étnico grave, como es en cualquier parte del mundo; terrible, porque hay mucho resentimiento, odio y desconfianza que se transmite de generación en generación, ya que nadie quiere vivir aplastado ${ }^{41}$.

\section{I.2.2 La Ley Antiterrorista}

El gobierno del Presidente Ricardo Lagos (2000-2006) afirmaba que no existía terrorismo en Chile. Sin embargo, el recurso de ese gobierno a leyes antiterroristas para ocuparse de las comunidades organizadas conllevó restricciones de las garantías procesales que los delitos cometidos no justifican generalmente. Además, el uso de acudir a tribunales militares para tratar los abusos policiales denunciados de que eran víctimas los mapuches impedía que obtuvieran resarcimiento. Es de saber que aún hoy, siguen

37. El diario El Austral de Temuco, 11 de abril de 1999, p. A-5.

38. La Ley Indígena $n^{\circ} 19.253$, Título V, párrafo $2^{\circ}$, artículo 36 .

39. Ibid., Título I, párrafo $3^{\circ}$, artículo 37 .

40. Ibid., Título I, párrafo $3^{\circ}$, artículo 36 .

41. El diario El Mercurio, 18 de marzo de 1999, p. C-3. 
siendo acusados y condenados conforme a una versión modificada de la Ley Antiterrorista implantada por el gobierno militar del General Augusto Pinochet. Los juicios plantean serias preocupaciones con respecto a las garantías procesales. El uso de los cargos de terrorismo hace que los líderes mapuches permanezcan en detención preventiva durante muchos meses.

El gobierno de Eduardo Frei (1994-2000) ya había iniciado algunos enjuiciamentos contra ellos, conforme a la Ley de Seguridad del Estado, una ley de 1958 destinada a combatir la subversión, la rebelión y la violencia política $^{42}$. En marzo de 2002, el senador por la Araucanía Alberto Espina instó a que se combatiera a los grupos mapuches:

con todo el rigor de la ley, ya que sus conductas han creado un estado de inseguridad y temor que es incompatible con el pleno funcionamiento del Estado de Derecho ${ }^{43}$.

El aumento del número de incidentes violentos en la zona indígena y la presión muy importante de los agricultores para una respuesta más firme hacen que el gobierno de Ricardo Lagos recurriera a la Ley Antiterrorista como alternativa más poderosa. Cabe observar que de acuerdo con la Constitución de Chile, los condenados por terrorismo no pueden ostentar un cargo público, ocupar puestos de enseñanza, ni practicar el periodismo durante un período de quince años. En una gran mayoría, los peores actos de los que se acusa a los mapuches son considerados en el Código Penal: destrucciones de propiedad privada, ataques incendiarios contra bosques, camiones y maquinaria de compañías madereras. En diciembre de 2000, se introdujo un nuevo Código de Procedimiento Penal en la Araucanía, caracterizado por un sistema acusatorio y los procedimientos escritos por juicios orales en tribunales abiertos mejorando la transparencia de los procesos penales.

La realidad jurídica es que el gobierno está presionado por demostrar resultados y que el objetivo de la Ley Antiterrorista es remediar la baja tasa de

42. Durante el gobierno de Eduardo Frei, numerosos mapuches enfrentaron cargos tales como incendio, robo, ocupación de tierras, secuestro. Algunos funcionarios públicos abrieron tres procesos diferentes con arreglo a la Ley de Seguridad del Estado. En diciembre de 1997, en respuesta a la petición oficial de la compañía forestal Arauco, el Intendente de la Araucanía, Oscar Eltit, ordenó el enjuiciamiento conforme a la Ley de Seguridad del Estado a los mapuches responsables del incendio de tres camiones cargados de madera propiedad de Arauco en Lumaco. Doce fueron arrestados y cinco fueron finalmente condenados de acuerdo con la LES y sentenciados a tres años de cárcel por desorden público.

43. Informe de la Comisión de Constitución, Legislación. Justicia y Reglamento del Senado, Boletín n S680-12, 9 de julio de 2003, p. 5. 
condenas derivadas de las investigaciones criminales en curso. Con las leyes ordinarias, a los fiscales les costó reunir pruebas suficientes para condenar a los responsables, mostrándose reticentes los testigos en prestar declaración por temor a represalias. Las disposiciones especiales antiterroristas permiten superar este obstáculo ocultando a los acusados, a sus abogados y al público en general, la identidad de los testigos: esto limita seriamente los derechos de los acusados y plantea el gran problema del uso de los testigos «sin rostro». El resultado es que, en caso de testimonio malicioso, la defensa no puede acusar de perjurio a testigos que no puede identificar. Más aún, en circunstancias extremas, los testigos pueden simplemente mentir con impunidad. Lo increíble es que esta manera dictatorial de aplicar la ley sigue vigente hoy en día, principalmente contra los mapuches.

Concretamente, ¿quiénes son los «terroristas» en Chile? Para el Estado, la respuesta está clara: son los mapuches que pertenecen a la Coordinadora de Comunidades en Conflicto Arauco Malleco. Esta organización se compone de comunidades que defienden reclamaciones de tierras, y se compromete a apoyar a todas las que estén involucradas en unos conflictos de tierras. Además, llama a la «reconstrucción de la nación mapuche» ${ }^{44}$ y ha adoptado una estrategia de «control territorial» $»^{45}$. La organización reconoce acciones violentas limitadas al ámbito de la defensa del Territorio y de la autodefensa de las comunidades. Aunque la causa parezca justa, es de suponer que aquellas acciones pueden llegar a ser también actos criminales que justifiquen unas investigaciones y sanciones penales. Frente al conflicto, el Presidente Ricardo Lagos creó en enero de 2001 la Comisión de Verdad Histórica y Nuevo Trato, compuesta de una veintena de representantes indígenas y no indígenas y presidida por el ex Presidente Patricio Aylwin. El objetivo era proponer una nueva política que abordara los problemas indígenas en Chile.

A pesar de todo, las cosas no evolucionan correctamente porque los conflictos continúan. La visita a Chile (julio de 2003) de Rodolfo Stavenhagen, Relador Especial de las Naciones Unidas para los derechos humanos y libertades fundamentales de los indígenas, muestra numerosos problemas. En su informe, pone de relieve una evidencia jurídica afirmando

bajo ninguna circunstancia deberán ser criminalizadas o penalizadas las legítimas actividades de protesta o demanda de las organizaciones y comunidades indígenas [...] no deberán aplicarse acusaciones de

44. Entrevista de Osvaldo González con un dirigente de la Coordinadora Arauko-Malleko, "La lucha mapuche es nacionalista, anticapitalista y revolucionaria», publicada en el periódico Resumen Latinoamericano, $\mathrm{n}^{\circ}$ 58, marzo-abril 2002.

45. Idem. 
delitos tomados de otros contextos (amenaza terrorista, asociación ilícita) a hechos relacionados con la tierra y los legítimos reclamos indígenas ${ }^{46}$.

proponiendo que:

el gobierno de Chile considere la posibilidad de declarar una amnistía general para los defensores de derechos humanos procesados por realizar actividades sociales y/o políticas en el marco de la defensa de las tierras indígenas ${ }^{47}$.

Aunque los fiscales niegan rotundamente que exista discriminación, la aplicación de la legislación antiterrorista a los mapuches involucrados en conflictos de tierras constituye un trato selectivo y desigual. De acuerdo con el artículo 26 del Pacto Internacional de Derechos Civiles y Políticos, Chile tendría que asegurarse de que todas las personas son iguales ante la Ley y tienen derecho sin discriminación a igual protección de la ley.

Aunque la Ley Antiterrorista nació bajo el regimen de Augusto Pinochet que quería tratar el terrorismo como un delito político o ideológico, las reformas de Aylwin eliminaron sus connotaciones políticas y lo tipificaron como un delito violento gravísimo contra personas. En efecto, para Aylwin, el terrorismo era «atentar contra la vida, la integridad física o la libertad de las personas por medios que produzcan o puedan producir un daño indiscriminado, con el objeto de causar temor a una parte o a toda la población» ${ }^{48}$. El delito que me parece más cuestionable es uno de los que se aplican con mayor frecuencia a los mapuches: el incendio, incluyendo hasta sus formas más leves. Los delitos bajo la Ley Antiterrorista incluyen incendiar edificios desocupados y bosques, mieses, pastos, monte, cierros o plantíos (artículo 476 del Código Penal).

Ahora bien, la Ley Antiterrorista en vigencia durante el gobierno militar no hacía referencia alguna al delito de incendio. Lo curioso es que fue introducida durante el debate del proyecto en una comisión de la Cámara de Diputados $^{49}$. El incendio está tipificado en el Código Penal en un capítulo

46. Informe del Relator Especial Rodolfo Stavenhagen, Naciones Unidas, Consejo Económico y Social, julio de 2003, p. 56 y 87.

47. Idem.

48. «Historia de la Ley n ${ }^{\circ}$ 19.027. Biblioteca del Congreso Nacional (1997)», citado en Bascunán Rodriguez, Antonio, El delito de incendio terrorista, Informe en derecho, Universidad de Chile, Facultad de derecho, Departamento de Ciencias Penales, 15 de octubre de 2003, p. 5.

49. Bascuñán Rodríguez, Antonio, El delito..., p. 9. 
que hace referencia a los delitos contra la propiedad, no refiriéndose a los delitos contra la persona. Pues se trata del único delito dentro de la Ley Antiterrorista que no representa una amenaza directa o deliberada contra la vida o la libertad. Esta inclusión dentro de la lista de los delitos de terrorismo es altamente cuestionable. La Constitución de Chile considera que «el terrorismo en cualquiera de sus formas es por esencia contrario a los derechos humanos» (artículo 9 de La Constitución de Chile), entonces, el uso de la legislación antiterrorista para tratar delitos de menor gravedad es incompatible con este principio constitucional.

Otro problema directamente ligado a la Ley Antiterrorista es la detención preventiva. Un detenido por cargos de terrorismo, aunque sea absuelto posteriormente, se enfrenta a largos períodos de prisión preventiva. Al decidir investigar un delito como un acto terrorista, el fiscal aumenta la probabilidad de que el sospechoso permanezca en prisión durante todo el período previo al juicio, o una parte considerable de éste. El nuevo Código de Procedimiento Penal permite revisiones periódicas de las órdenes de prisión preventiva en las que el acusado puede obtener eventualmente la libertad provisional. De hecho, si se solicita una vista después de que hayan transcurrido más de dos meses desde la última vista de este tipo, el tribunal debe estar de acuerdo (artículo 144). A continuación, una vez que han transcurrido seis meses desde la última vista, el propio tribunal tiene que ordenar una vista para decidir si debe continuar el encarcelamiento (artículo 145).

Sin embargo, es lógico pensar que si el fiscal puede demostrar que el delito es grave (incendio terrorista por ejemplo), los jueces aprueban una orden para el encarcelamiento del acusado sin más. De hecho, incluso en los juicios penales ordinarios, los abogados defensores criticaron a los fiscales por exagerar los cargos con el fin de prolongar injustamente el período de detención preventiva.

Así, pues, ¿nos comprometeríamos al decir que algunas leyes fueron desviadas para alcanzar otro objetivo? ¿no sería el pueblo mapuche el blanco verdadero? ¿El otro, el que difiere? Y sobre todo los que llevan a cabo una lucha secular por su libre determinación y un respeto mutuo. La utilización hábil o malintencionada de ciertas leyes ¿ no estaría al servicio del desarrollo económico, no basado en la riqueza cultural del pueblo chileno en su diversidad sino en el culto moderno del dinero, la dominación, la propiedad individual, y la destrucción progresiva de los indios? Cuesta creerlo. Los chilenos son lo suficientemente inteligentes como para dejar de lado y no destruir a los actores de una historia que hacen de ellos lo que son actualmente. 


\section{LA LEY DE LA FUERZA}

Hasta ahora, hemos visto las repercusiones de la ley frente al problema mapuche. Mientras que la ley debería oponerse a la fuerza, en nuestro segundo apartado, vamos a ver cómo la fuerza fue utilizada para domar a los mapuches y, a veces, constatar que la Ley del Estado se vincula desgraciadamente con la fuerza y recíprocamente. En efecto, a menudo, el mapuche fue asimilado a palabras peyorativas heredadas de la historia chilena, la visión estatal negativa, la incomprensión colectiva o de un racismo subyacente. Vamos a mostrar cómo la fuerza fue utilizada para embozar a los mapuches defensores de sus tierras, y poner de relieve de qué manera la ley pudo convertirse en una protección ideal para todos tipos de exacciones por parte de algunos de sus representantes.

\section{II.1 La responsabilidad policíaca}

Las fuerzas de orden público se enfrentan a menudo con protestas mapuches lo que significa que las tensiones son importantes. Si razonamos cívicamente, los servidores de la ley deben asegurarse de que la fuerza sólo se use cuando lo justifica la situación y de manera proporcional al riesgo físico que corren. La falta de respeto en contra de los mapuches, los insultos o calificativos racistas no sólo representan un delito sancionable en teoría por la ley, sino que también aumentan las tensiones existentes y refuerzan los resentimientos. La realidad es que cuando numerosos efectivos de Carabineros vienen a ver a las comunidades mapuches para proceder a detenciones, a veces los maltratan físicamente insultando además a las mujeres, niños y ancianos.

Por otra parte, hay que tomar en cuenta los casos de tortura bajo custodia policial después de la detención. Parece que estos tipos de malos tratos han disminuido a partir de la aplicación del nuevo Código de Procedimiento Penal en Araucanía. Normalmente, todas las denuncias de uso excesivo de la fuerza por parte de Carabineros son investigadas por fiscales militares y juzgadas en procesos escritos secretos ante tribunales militares. Está claro que estos tribunales no ofrecen a las víctimas de abusos policíacos las garantías para una investigación imparcial. Por eso, las denuncias no se resuelven y finalmente no se sanciona a los responsables. El desfase entre el enjuiciamento de los mapuches que quebrantan las leyes y la impunidad de que gozan los funcionarios encargados de hacer cumplir la ley, es una prueba flagrante del trato desigual, haciendo de los mapuches un problema de gran amplitud y «aparte». 
José Osvaldo Cariqueo Saravia, lonko de la Comunidad mapuche, tiene una casa al lado de una vasta plantación de árboles. Fue detenido, acusado de asociación terrorista mientras que sus dos hermanos cumplían una condena de diez ańos de prisión por un ataque incendiario ${ }^{50}$. Lorenza Saravia era la madre de los tres hermanos y tenía ochenta y seis años. Dijo al Programa de Derechos Indígenas en 2003 que la policía había allanado la comunidad cinco veces en busca de sus hijos y que

me llevaron presa, me pasaron arrastrando por un montón de piedras, me tiraron al furgón como a un saco de papas y me pegaron como dos palmetazos en la cara. Carabineros tendrán derecho a pegarle a una mujer vieja ${ }^{51}$.

Un anciano, Luis Licán miembro de la comunidad de José Guiñón, recibió el impacto de un balín disparado por un carabinero durante un allanamiento policial, el 15 de agosto de 2003. Luis Licán murió meses después del allanamiento y no existen pruebas claras que conecten su muerte con ese maltrato, aunque la comunidad está convencida de la relación.

Los allanamientos policiales se relacionan por lo general con conflictos de tierras. Flora Collonao, casada con el lonko de la comunidad de Temulemu (cerca de Traiguén) Pascual Pichún, experimentó siete incursiones impresionantes. Conviene notar que su marido y sus dos hijos fueron encarcelados so color de amenazas terroristas durante cinco ańos. Esta mujer animosa nos cuenta el allanamiento del 11 de marzo:

No alcancé a abrir la puerta, y ellos a puras patadas me abrieron la puerta, me desarmaron la puerta. Me quebraron el vidrio. [...]. La policía diciendo: Levántese mierdas de la cama. [...]. Cuando llegó Investigaciones me esposaron, me tiraron como animal arriba de la camioneta $^{52}$.

Cabe señalar que a partir de 2002, se denunciaron muchos otros incidentes de ese tipo por parte de los Carabineros durante operaciones de detención y el uso excesivo de la fuerza para desalojar a los mapuches que ocupaban tierras en disputa. Los Carabineros son conscientes de estos problemas desde

50. El diario El Mercurio, "Juicio por Incendio Terrorista: Caza de Mapuches rebeldes», 30 de julio de 2004 .

51. Programa de Derechos Indígenas. Instituto de Estudios Indígenas, Allanamientos policiales en la comunidad José Guiñón, Universidad de la Frontera, Temuco, agosto de 2003.

52. Programa de Derechos Indígenas. Instituto de Estudios Indígenas, Los allanamientos del domicilio de la familia Pichún de Temulemu y el encauzamiento del denominado conflicto mapuche, Universidad de la Frontera, Temuco, 17 de marzo de 2004. 
hace varios años, pero nada se hace. Una carta enviada por el jefe de la Novena Zona de Carabineros (General Mauricio Catalán) a la Prefectura de Cautín señala:

Trato grosero, ofensivo, vejatorio y altanero, tanto de los seńores jefes, oficiales y personal, hacia los subvertores del orden, especialmente de la etnia mapuche. Se puede apreciar con absoluta claridad que el personal de Carabineros llega al lugar de los hechos con un ánimo confrontacional predispuesto e incluso en más de algún procedimiento ha sido la actuación policial desmedida y prepotente la que ha provocado la reacción de los mapuches, situación que es inaceptable en nuestra institución. [...] los agentes ignoran el concepto de la defensa legítima ${ }^{53}$.

A pesar de la existencia clara de un comportamiento inhumano de los Carabineros, las cosas siguen agravándose. El 25 de julio de 2004, un contingente de cincuenta policías armados se desplazó en un autobús y llegó a la casa de Irma Lleuvul Cherquián (en Itinento, distrito de Padre de las Casas) que estaba sola con sus cuatro hijos. La policía, armada con subametralladoras y acompańada por un fiscal, desordenó toda la casa, rompiendo muebles y material escolar de los niños. No dieron ninguna explicación por su acción, ni mostraron una orden de registro. Por fin, es de notar la desaparición de dos anillos de oro guardados en un sobre, un regalo de los abuelos a Irma. Otro caso fue cuando treinta policías allanaron la casa de Rosa Quinel Chicahual y Alberto Catrilaf Parra de setenta y sesenta años respectivamente, que estaban con sus tres hijos menores. Los policías amenazaron a la pareja con sus armas, los empujaron y los acorralaron con sus escudos mientras registraban la casa sin presentar ninguna orden de detención o registro ${ }^{54}$.

No obstante, debemos saber que el Código de Procedimiento Penal prohibe el uso de cualquier método de interrogatorio que «menoscabe o coarte la libertad del imputado para declarar» y prohibe explícitamente "todo método que afecte la memoria o la capacidad de comprensión y de dirección de los actos del imputado, en especial cualquier forma de maltrato, amenaza, violencia corporal o psíquica, tortura, engaño, o la administración de psicofármacos y la hipnosis» ${ }^{55}$. El juez de garantías puede tomar medidas

53. Palomera, Fredy y Lezaeta, Pedro, «Documento que revela mea culpa de Carabineros en maltrato a mapuches», La Tercera de la Hora, Temuco, 24 de noviembre de 2000.

54. El diario El Gong, "La represión continúa en Xuf Xuf», Araucanía, 9 de agosto de 2004.

55. Artículo 195 del Código de Procedimiento Penal. 
para garantizar la protección del acusado en cualquier etapa del proceso. Como protección final y como último recurso, la Corte Suprema puede anular juicios que hayan incumplido de manera significativa los derechos de los acusados garantizados por la Constitución, las leyes y los tratados internacionales ratificados por Chile.

\section{II.2 La fuerza: un arma que desafía el tiempo}

Desde los principios de la conquista de Chile por los espańoles (1541) hasta hoy en día, la fuerza ha sido el instrumento más utilizado para domar a los mapuches. Los siglos pasaban pero el uso de la fuerza contra los indígenas iba reforzándose por razones que no entran en la reflexión del presente trabajo. Sólo se puede constatar que el punto común de la guerra entre mapuches y españoles y luego entre mapuche y chilenos, era la tierra. Por eso, los importantes problemas que persisten hasta ahora se deben en gran mayoría a lo que llama eufemísticamente el Estado chileno: la Pacificación de La Araucanía.

El primer punto a tomar en cuenta es la expansión progresiva de la economía agraria desde el centro del país hacia el sur. Muchos colonos traspasaron pacíficamente el río frontera Bío-Bío para ocupar tierras entre los mapuches: fue una como colonización hormiga y silenciosa que estaba avanzando sobre las tierras indígenas. El segundo punto consistió en la ocupación de la línea militar del río Malleco que provocó la intranquilidad de los mapuches. Poco después, siguió una sublevación general de los arribanos (vecinos del norte del río Bío-Bío)

que dio lugar a quince años de guerra, culminando la ocupación definitiva de La Araucanía y la pérdida de los territorios independientes mapuches $^{56}$.

Luego, la ocupación del territorio mapuche del Bío-Bío al sur se planificó gracias a la fuerza (1870), cuando el Estado chileno inventó distintas estrategias para conquistarlo y ocuparlo de forma definitiva. Durante los primeros años, los ejércitos chileno y argentino acorralaron a los indígenas en la Cordillera de los Andes. Así, con la intervención de la fuerza militar, lograron ocupar la provincia de Arauco y fundaron en la actual provincia de Malleco, varias ciudades. Los militares se dedicaron a la ocupación del territorio mapuche con la creación de fuertes. La clara intención de las

56. José Bengoa, Historia del Pueblo Mapuche, Editorial Sur, Santiago, 1996, p. 151. 
autoridades políticas chilenas era que ni los militares ni los colonos se fueran de allí lo que significaba la pérdida de la independencia de esta nación:

Desde la ocupación militar de nuestro territorio, el Estado Nación chileno a través de su aparato ideológico, despojó a nuestras autoridades originarias de su poder político y social relegándolas a ocupar posiciones subalternas para conseguir la consolidación de la plena soberanía estatal sobre nuestro pueblo ${ }^{57}$.

Los movimientos sociales y políticos de Chile cometieron errores en el tratamiento de esa sociedad, mostrando de nuevo su falta de conocimiento de la particularidad histórica de ese pueblo. Los chilenos se transformaron en nuevos colonizadores que quisieron quitar a los indígenas su derecho a la libertad e independencia. A partir de la derrota militar de 1881, los mapuches debieron someterse al rigor de la "civilización», sinónimo para ellos de «años de temor, de pestes, de hambre, de pérdida de una identidad ${ }^{58}$.

Es pertinente afirmar también que la guerra del Pacífico (1879) favoreció aún más la violencia. En efecto, los mapuches se sintieron un poco más libres por ser menos importante la presencia militar. Además, varios colonos empezaron a cometer abusos y particularmente, la violación de jóvenes mapuches. Tales acontecimientos provocaron una sublevación general que fue repelida con violencia. Los mapuches atacaron entonces el fuerte de Lumaco el 5 de noviembre de 1881. Trece de ellos fueron apresados y estuvieron confinados en dos celdas. Y durante la noche, mataron a un soldado (Juan Evangelista Fuentes) con un golpe de palo en la cabeza. Todos los mapuches fueron asesinados y los cadáveres fueron abandonados desnudos, cerca del fuerte de Lumaco. Hoy en día cabe preguntarse, ¿cómo reaccionan los mapuches ante la utilización de la fuerza? Conocemos la capacidad negociadora y, en poca medida, la malicia indígena, pero no se puede negar la existencia dentro de la comunidad de un pequeño núcleo que lucha con bombas Molotov. Ahora bien, no por ello no se puede hacer la pregunta ¿sería legítimo tener a los mapuches por terroristas? o ¡asimilarlos a un grupo terrorista?

El riesgo era que se asociaran con terroristas para dar un nuevo impulso a su lucha. Sin embargo, la E.T.A o el I.R.A, son organismos que actúan en un medio totalmente diferente. Las comunidades no necesitan esas prácticas. Tienen los suficientes argumentos que les dan fuerza y legitimidad para reclamar sus derechos sin recurrir a la fuerza. Los mapuches eran percibidos

57. Aukiñ Wallmapu Ngulam, El pueblo mapuche..., p. 57.

58. Bengoa, José, Historia del Pueblo..., p. 329. 
como personas que no son capaces de pensar, analizar, ni de proyectar su situación. Esa mentalidad muy opresora todavía persiste en la sociedad chilena. En realidad, es el sentimiento de culpabilidad que subyace en la mente de muchos chilenos, y que se manifiesta a distinto nivel en los hechos conflictivos con los mapuches. El señor Walter Riesco, presidente de la Confederación de la Producción y del Comercio, resume muy bien la situación mapuche diciendo «mire, los mapuches no tienen ningún derecho en este país»" ${ }^{59}$. El sentido de culpabilidad histórica explica muchas cosas. En definitiva, no hubo ningún avance para tratar algunas temáticas que podrían ser provechosas para todos, porque cada uno tiene su propia versión sobre los mapuches. Los chilenos no se dieron cuenta de que estaban tratando con otra gente, con otra cultura, que tiene otros comportamientos y otras formas de medir las cosas.

Si aparece claramente la no implicación del pueblo mapuche con organismos terroristas, ¿cómo explicar sus relaciones con la ultraizquierda ${ }^{60}$ ? En marzo de 1999, el senador de la Unión Democrática Independiente, Carlos Bombal, afirmaba que la pobreza no era el principal detonante de las expresiones mapuches de rebeldía, porque la verdadera razón estaba en la influencia política de la ultraizquierda. Aseguró que una rama descolgada del Movimiento de Izquierda Revolucionaria, el Ejército de liberación de los Pobres «Patria Libre», tuvo por estrategia la canalización de la lucha de izquierda para los próximos años a través de lo que denominan «la revolución de los pueblos originarios». El concepto era el establecimiento de la lucha armada de las comunidades de base indígenas, con una preparación ideológica, armada y comunicacional de los jóvenes. Carlos Bombal enfatiza afirmando :

el discurso, con fuerte contenido ecológico y asociado a una cosmovisión mapuche, se basa en la propiedad de la tierra y la existencia de un territorio usurpado por el Estado ${ }^{61}$.

Lo importante fue que el general Mauricio Catalán, jefe de la Novena Zona Policial de Carabineros, descartó que en el sector de Traiguén (donde se registró la mayor parte de acciones mapuches), hubiera una presencia

59. Las declaraciones del Señor Walter Riesco fueron publicadas en varios medios periodísticos, entre el 9 y el 10 de marzo de 1999 (Barrera, Aníbal, El grito mapuche... p. 56).

60. Las primeras sospechas de las relaciones entre los mapuches y una rama política aparecieron en el diario La Tercera de la Hora, parecido en 10 de marzo de 1999.

61. El diario El Austral de Temuco, 29 de marzo de 1999, p. B-5. 
terrorista o extranacional. Lo denunciaba también el diputado de Renovación Nacional, Gustavo Alessandri :

Si alguien tiene los antecedentes, que los proporcione a la policía para de esta manera mejor investigar y poder determinar quiénes son los responsables de las situaciones que se han producido en la zona $^{62}$.

La pobreza y la marginalidad de los mapuches no tienen nada que ver con esos supuestos activadores del conflicto. La miseria de este pueblo indígena, que es imputable casi absolutamente al Estado chileno, es el único detonador de lo que estaba ocurriendo en la ruralidad de las regiones Octava y Novena. En resumidas cuentas, existía una clara efervescencia entre los mapuches más jóvenes que veían un futuro muy dudoso, carente de oportunidades. Los conflictos eran generalmente dirigidos por líderes locales entre los cuales algunos optaban por la negociación, y otros por acciones más radicalizadas. Hay que notar también la presencia de personas de otras nacionalidades en las áreas de conflicto, que, a veces, se involucraron en hechos contrarios al orden público. Sin embargo, como se puede leer en un artículo,

el aspecto fundamental de los conflictos en Traiguén es la disputa de 58,4 hectáreas del fundo Santa Rosa de Colpi [...]. A esa porción, la comunidad de Temulemu afirma tener derechos y señala que un fallo de 1930, dictado por el entonces Tribunal de Indios, así lo reconocía ${ }^{63}$.

A pesar de todo eso, el subsecretario del Interior, Guillermo Pickering, seguía poniendo de realce que «en Chile, no tenemos comandantes, porque tampoco tenemos Chiapas, ni tenemos revolución, ni un estado de sublevación mapuche» ${ }^{64}$.

\section{II.3 La paradoja de la fuerza}

El pueblo mapuche tiene sus propios héroes y heroínas, sus banderas y su propia fecha de independencia que celebrar, anterior a la creación de los Estados de Chile y Argentina. La lucha y voluntad del mapuche de hacer valer y mantener su independencia, se remonta a tiempos muy antiguos,

62. El diario El Austral de Temuco, 14 de abril de 1999, p. A-6.

63. El diario El Mercurio, 17 de marzo de 1999, p. C-3.

64. El diario El Austral de Temuco, 20 de abril de 1999, p. A-7. 
valores que ya antes de la llegada de los europeos al continente americano, habían sido puestos a prueba: en 1458, el imperio inca trató de integrar el territorio mapuche sufriendo al igual que los españoles un fracaso rotundo en sus intentos colonialistas. Mucho más tarde, España reconoció la independencia de la nación mapuche el 6 de enero de 1641 en el tratado Quillín, fijándose como frontera, entre las dos naciones, el río Bío-Bío. España capitulaba ante su propia impotencia y renunciaba a sus designios de conquistar los territorios más allá de la frontera establecida, frontera, al fin y al cabo, impuesta por los mapuches.

El 6 de enero de 2007, se cumplió el 366 aniversario de la independencia mapuche gracias a la determinación del pueblo originario de no aceptar la esclavitud y servidumbre que le ofrecían los colonialistas europeos y más tarde sus descendientes. La Comunidad mapuche fue la primera nación independiente del continente americano y la última en ser "conquistada». La fuerza estatal empleada con respecto a estas comunidades acarrea un resultado contrario porque siguen más que nunca los pasos hacia su independencia. Muy fuertes son el respeto y carińo por su mapu (tierra), que era considerado como el rewe, altar sagrado que no puede ser violentado, así como lo es su derecho a la libredeterminación. Estos principios siguen siendo infrangibles y podemos añadir aun que van cobrando más fuerzas: están en el alma de cada mapuche.

Los siglos de agresión de España, Chile y Argentina, no han logrado ablandar el espíritu de lucha del pueblo Mapuche. De hecho, la fuerza y los insultos no han podido quebrantar su resistencia porque emerge de la tierra misma, y viene de una herencia histórica. A pesar de todo lo que sigue sufriendo esta nación, confía en el futuro, porque la verdad, la razón y la justicia, tarde o temprano terminarán por imponerse.

Lo que está sucediendo hoy en día, es que el común de los chilenos empieza a entender, al parecer, lo que ocurre con los mapuches. Una encuesta del Centro de Estudios de la Realidad Contemporánea en abril de 1999 puso de manifiesto que un ochenta por ciento de quienes han sido consultados cree en la legitimidad de las protestas de las comunidades mapuches $y$, particularmente, las que se dirigen contra las empresas forestales. El CERC, dirigido por Carlos Huneeus, es una Corporación Privada, independiente y sin fines de lucro, que realiza encuestas de opinión pública desde 1986, con especial énfasis en el estudio del desarrollo político y los cambios económicos. Desde 1995, ha llevado a cabo encuestas nacionales para conocer los cambios de opinión de los chilenos sobre la política, la economía, la sociedad y sobre los principales temas de la coyuntura del trimestre anterior a la encuesta. 
Los resultados son analizados y entregados al Barómetro CERC que es un producto único y que se adquiere por suscripciones.

Así, el chileno medio se da cuenta de que las forestales pueden contar con la legalidad, pero no con la legitimidad. Eso significa que la mayor parte de los chilenos cree en la deuda histórica que el país tiene con el indio mapuche. Más aún, diríase que ellos creen que se les deba hacer justicia ahora. Prueba de ello es que la solución al problema mapuche debería pasar por una consulta nacional. La fuerza, aún utilizada hoy contra ellos, ha tenido y tiene efectos inversos, y acaba por sensibilizar a lo largo de los años la opinión de una gran parte de chilenos que está a favor de una vía más humana y sobre todo, más democrática. Con mayor razón, es de pensar que seguirán desapareciendo, aunque lentamente, los estigmas de la dictadura. Los chilenos parecen más sensibles a los problemas de esta minoría y el tiempo juega a favor de los mapuches y sus reivindicaciones. Por otro lado, no podemos dejar de lado esta paradoja según la cual la violencia va a continuar con una dinámica proliferante y demasiado peligrosa. Detenerla es un tema que pide reales esfuerzos de inteligencia y voluntad y la pregunta importante es de saber: ¿quién gana realmente terreno hoy: ¿el Estado Chileno o los mapuches?

Al fin y al cabo, ¿̨no convendría proponer otra formulación del título de este artículo asociando la copulativa $\mathrm{Y}$ y la disyuntiva $\mathrm{O}$ para traducir mejor las dificultades del pueblo chileno, sea indígena o no, par construir un Chile respetuoso de las legítimas aspiraciones de sus componentes?

Desde 1541 hasta hoy, la gente que ha vivido al lado de los mapuches no ha sabido ceñirse a las reglas de tolerancia y respeto. Compartir un porvenir implica aprehender mejor la cultura ajena, imbuirse de ella para poner en evidencia un futuro a dos, un futuro común a indígenas y chilenos. La fuerza de la ley y la ley de la fuerza no han permitido encontrar un compromiso humano, respetable y constructivo entre los antiguos y nuevos ocupantes de Chile. Sin embargo, la razón es clara y sencilla y viene de la representación cultural mapuche: la tierra es la base de su existencia. Por consiguente, hablar de ley o de fuerza cuando se alude a la tierra de las generaciones mapuches, es una noción abstracta, privada de sentido y coherencia. Por eso, esta Comunidad no entiende el ensañamiento ilógico de las autoridades chilenas, y desde una visión exterior de la situación, comprendemos que no hablan la misma lengua. No olvidemos que los mapuches jamás dejaron de luchar por conservar sus tierras: en otras palabras, «son la tierra».

Dicho aspecto cultural lo condiciona todo. Merecer el reconocimiento de la Comunidad mapuche, pasaría por mucha humildad, reconocimiento, y reflexión por parte de las autoridades chilenas. Pero la verdadera pregunta es: ¿qué quiere Chile? ¿Una solución unilateral al problema, negando que 
existen también minorías o un esfuerzo más que importante, histórico, entre todas las voces diferentes del país para crear un solo núcleo respetuoso de las diversidades? Sólo la restitución completa y sin condición de la tierras necesarias a los mapuches por parte del Estado chileno podría iniciar una nueva era relacional entre indios y chilenos. Uno de los grandes fallos del gobierno chileno ha sido y es, el de tener en poco a este pueblo como si fuera un pelele que se podría manipular a discreción. Intentar solucionar el problema mapuche pasaría por la paralización total de las faenas forestales, la reconstrucción de las viviendas destruidas por los Carabineros, la indemnización a todas las personas afectadas por la violencia innecesaria de Carabineros, la indemnización por los daños al ecosistema causados por las forestales, la bonificación por las plantas nativas destruidas y la verificación de los límites de las comunidades que están en conflicto.

A mediano y largo plazo, sería imprescindible la paralización de la plantación de pinos y eucaliptos en todo el territorio mapuche del Bío-Bío al sur, un plan estatal de expropiación de tierras en todos aquellos lugares en que los dueños se nieguen a traspasarlas a las comunidades, la entrega de un porcentaje del Presupuesto Nacional para el desarrollo de la nación mapuche y el reconocimiento de la estructura original de las comunidades. Además, el gobierno chileno debería obrar por el reconocimiento constitucional del pueblo mapuche con la puesta en marcha de los tratados internacionales de defensa de las minorías originarias y la Declaración Universal de los Derechos Humanos.

Los mapuches son conscientes de que la política educacional actual del Estado chileno propone una como uniformidad cultural y lingüística que responde a intereses ajenos al ser mapuche. La actual convivencia entre indígenas y chilenos está marcada por una completa intolerancia cultural y la incomprensión social, verdaderas consecuencias de las diversas políticas de los gobiernos chilenos. Con razón lo subraya Aníbal Barrera, "esto ha negado la historia e identidad tanto del pueblo mapuche como del chileno" ${ }^{65}$. Concluiremos el presente trabajo recordando el comentario del historiador temuquense Jaime Flores que resume, a mi juicio, la complejidad del problema:

Chile continúa anclado a una especie de nacionalismo anticuado. [...]. No estamos acostumbrados a que el otro nos contradiga, y menos si lo percibimos como inferior. [...]. El Estado y los chilenos en general debemos asumir que los mapuches y el resto de las etnias originarias, no son un obstáculo para el progreso como se pensó desde el siglo pasado.

65. Aníbal Barrera, El grito mapuche... p. 166. 


\section{BULLETIN HISPANIQUE}

\section{BibliografíA}

\section{Fuentes generales}

Alonqueo Piutrin Martín, Mapuche Ayer y Hoy, Editorial Padre las Casas, Temuco, Chile, 1985.

Barrera Aníbal, El grito mapuche (una historia inconclusa), editorial Grijalbo, Santiago de Chile, 1999.

Bascuñán Rodríguez Antonio, El delito de incendio terrorista, Informe en Derecho, Universidad de Chile, Facultad de Derecho, Departamento de Ciencias Penales, 15 de octubre de 2003.

Bengoa José, Historia de un conflicto: El Estado y los Mapuches en el Siglo XX, Editorial Planeta, Chile, 1999.

- Historia del Pueblo Mapuche, Editorial Sur, Santiago, 1996.

Colicoy Aniulén Domingo, Estado chileno - sociedad mapuche, VII Congreso Internacional del CLAD sobre la reforma del Estado y de la Administración Pública, Lisboa, Portugal, 2002.

Correa, Martín, La Reforma Agraria y las Tierras Mapuches: Chile 1962-1975, LOM ediciones, Chile, 2005.

Durán Ruth, González Claudio, Tello Andrés, La comunidad mapuche: colonización jurídica-legal y resistencia del estar en común, Departamento de Sociología y Antropología, Centro Regional de Estudios Étnicos y Rurales (CREER), Universidad de Concepción, Chile, 2006.

Informe de la Comisión de Constitución, Legislación. Justicia y Reglamento del Senado, Boletín no S680-12, Chile, 9 de julio de 2003.

Informe del Relator Especial Rodolfo Stavenhagen, Naciones Unidas, Consejo Económico y Social, julio de 2003, p. 56 y 87.

Instituto de Estudios Indígenas de la Universidad de la Frontera, Informe del Programa de Derechos Indígenas en Chile, LOM ediciones, Temuco, Chile, 2003.

Lipschutz Alejandro, La comunidad Indígena en América y en Chile, Editorial Universitaria, Santiago de Chile, 1959.

Ortiz Claudia, El derecho de Dominio en la Legislación Indígena, Memoria de Grado de Licenciada en Ciencias Jurídicas y Sociales, Universidad de Concepción, 2001.

Programa de Derechos Indígenas. Instituto de Estudios Indígenas, Allanamientos policiales en la comunidad José Guiñón, Universidad de la Frontera, Temuco, Chile, agosto de 2003.

Programa de Derechos Indígenas. Instituto de Estudios Indígenas, Los allanamientos del domicilio de la familia Pichún de Temulemu y el encauzamiento del denominado 
conflicto mapuche, Universidad de la Frontera, Temuco, Chile, 17 de marzo de 2004.

Salazar Gabriel, Historia contemporánea de Chile, LOM ediciones, Chile, Tomo II, 1999.

Wallmapu Ngulam Aukiñ, El pueblo mapuche, su Territorio y sus Derechos, editorial Kolping, Temuco, Chile, 1997.

\section{Fuentes jurídicas}

Artículo 195 del Código de Procedimiento Penal.

La Ley Indígena $n^{\circ}$ 19.253, Editorial Pillan, Chile, 1993, Título I, párrafo $3^{\circ}$, artículo 7.

La Ley Indígena $n^{\circ}$ 19.253, Editorial Pillan, Chile, 1993, Título I, párrafo $3^{\circ}$, artículo 8.

La Ley Indígena $n^{\circ}$ 19.253, Editorial Pillan, Chile, 1993, Título I, párrafo $3^{\circ}$, artículo 36.

La Ley Indígena $n^{\circ}$ 19.253, Editorial Pillan, Chile, 1993, Título I, párrafo $3^{\circ}$, artículo 37.

La Ley Indígena $n^{\circ}$ 19.253, Editorial Pillan, Chile, 1993, Título II, párrafo $1^{\circ}$, artículo 12.

La Ley Indígena $n^{\circ}$ 19.253, Editorial Pillan, Chile, 1993, Título II, párrafo $1^{\circ}$, artículo 13.

La Ley Indígena $n^{\circ}$ 19.253, Editorial Pillan, Chile, 1993, Título II, párrafo $1^{\circ}$, artículo 19.

La Ley Indígena $n^{\circ} 19.253$, Editorial Pillan, Chile, 1993, Título IV, párrafo $1^{\circ}$, artículo 39.

La Ley Indígena $n^{\circ}$ 19.253, Editorial Pillan, Chile, 1993, Título V, párrafo 2º artículo 36.

\section{Fuentes periodísticas}

La Tercera de la Hora, 10 de marzo de 1999.

El Mercurio, 17 de marzo de 1999.

El Mercurio, 18 de marzo de 1999.

El Austral, Temuco, 29 de marzo de 1999.

El Austral, Temuco, 14 de abril de 1999.

El Austral, Temuco, 20 de abril de 1999.

La Tercera de la Hora, Temuco, 24 de noviembre de 2000.

Resumen Latinoamericano, N58, marzo-abril 2002.

El Mercurio, 30 de julio de 2004.

El Gong, Araucanía, 9 de agosto de 2004. 